\title{
PENGARUH KUALITAS DAN PELATIHAN MANAJER TERHADAP PENGEMBANGAN UPJA DI KABUPATEN PANGANDARAN
}

\section{EFFECT OF QUALITY AND MANAGER TRAINING TOWARD DEVELOPMENT OF AGRICULTURAL EQUIPMENT AND MACHINERY SERVICES IN PANGANDARAN REGENCY}

\author{
Garin Nur IImi ${ }^{1}$, Kusno ${ }^{2}$, Intan Kusuma Wardani ${ }^{3}$, dan Erniati ${ }^{4}$ \\ 1,2Mahasiswa Politeknik Pembangunan Pertanian Bogor \\ 3,4 Dosen Politeknik Pembangunan Pertanian Bogor \\ Korespondensi penulis, E-mail: intankusuma@pertanian.go.id
}

Diterima:

Disetujui terbit:

\begin{abstract}
The quality and amount of training for agricultural equipment and machinery services managers are low. Therefore, a study was conducted aimed at identifying the influence of quality and training of agricultural equipment and machinery services manager in the Pangandaran Regency. Data were collected using a questionnaire. The research data were analyzed using descriptive analysis and F-test. The population in this study is 40 respondents, which consist of the head and employee of an agricultural government, the head of agricultural equipment and machinery services, and farmers'. F-test results show the calculated $F$ value is $25.53>F$ table (3.24). It can be concluded that the quality of agricultural equipment and machinery services' management and training has a positive and significant effect on the development of agricultural equipment and machinery services.
\end{abstract}

Keywords: agricultural equipment and machinery services, equipment and machinery, manager training, manager quality

\begin{abstract}
ABSTRAK
Kualitas dan jumlah pelatihan terhadap manajer Usaha Pelayanan Jasa Alat dan Mesin Pertanian (UPJA) rendah. Oleh karena itu, dilakukan penelitian yang bertujuan untuk mengidentifikasi pengaruh dari variabel kualitas dan pelatihan manajer UPJA di Kabupaten Pangandaran. Data dikumpulkan menggunakan kuesioner. Data penelitian dianalisis menggunakan analisis deskriptif dan Uji F. Populasi dalam penelitian ini berjumlah 40 responden yang terdiri dari kepala dan penyuluh dari Balai Penyuluhan Pertanian, Kepala UPJA dan petani. Hasil UJI F menunjukan nilai F hitung $25.53>\mathrm{F}$ tabel 3.24. Hal ini dapat disimpulkan bahwa kualitas manajer dan pelatihan manajer UPJA berpengaruh positif dan signfikan terhadap pengembangan UPJA.
\end{abstract}

Kata kunci: alat dan mesin pertanian, kualitas manajer, pelatihan manajer, UPJA 


\section{PENDAHULUAN}

Alat dan mesin pertanian (alsintan) di Indonesia sangat beragam jenisnya dari prapanen, panen hingga pasca panen. Semakin meningkatnya produksi pertanian juga mempengaruhi tingkat kebutuhan alsintan. Oleh karena itu, diperlukan adanya dukungan dari berbagai sarana dan prasarana yang efektif. Alsintan mampu meningkatkan produktivitas dan efisiensi dalam bidang pertanian khususnya secara ekonomis dan sumberdaya. Di samping itu, peningkatan kualitas dan diversifikasi produk alsintan juga mampu menghasilkan nilai tambah tinggi dalam mendukung program pengembangan agribisnis.

Berdasarkan Permentan No. 25 tahun 2008 tentang Pedoman Penumbuhan dan Pengembangan Usaha Pelayanan Jasa Alat dan Mesin Pertanian (UPJA), pengertian UPJA adalah suatu lembaga ekonomi perdesaan yang bergerak di bidang pelayanan jasa dalam rangka optimalisasi penggunaan alat dan mesin pertanian untuk mendapatkan keuntungan usaha baik di dalam maupun di luar kelompok tani atau gapoktan.

Keberadaan UPJA dapat mengatasi kebutuhan alsintan bagi petani dan juga menjadi solusi dalam mengatasi kelangkaan tenaga kerja. Pada kegiatan ekonomi, UPJA mampu memberikan pelayanan jasa alsintan untuk budidaya pertanian sehingga dapat meningkatkan efisiensi kerja dan kesejahteraan petani.

Perkembangan UPJA masih memiliki keterbatasan dalam sistem pengelolaan yang disebabkan karena rendahnya keterampilan manajer, operator, dan tenaga administrasi. Pengembangan dan pembinaan dapat dilakukan dengan cara pelatihan UPJA. Pelatihan ini dapat meningkatkan kemampuan kelembagaan UPJA baik dari aspek teknis, ekonomis, dan administrasi pengelolaan UPJA.

Hasil penelitian yang dilakukan oleh Hamidah dan Soedarto (2006), menunjukan bahwa UPJA di Kabupaten Gresik berhasil mencapai kelayakan usaha disebabkan beberapa faktor penting antara lain: 1) kemampuan dan inisiatif manajer untuk berfikir komersial, 2) kemampuan operator, 3) kualitas pelayanan, 4) usaha menyediakan modal, dan 5) keaktifan melakukan konsultasi.

Oleh karena itu, penelitian ini bertujuan untuk menganalisis pengaruh pelatihan dan kualitas manajer terhadap perkembangan UPJA di Kabupaten Pangandaran. Luaran penelitian berupa identifikasi 
masalah dijadikan sebagai dasar untuk menyusun rekomendasi strategi sebagai masukan bagi perkembangan UPJA di Kabupaten Pangandaran.

\section{METODE PENELITIAN}

Responden penelitian berjumlah 40 orang yang terdiri atas adalah empat Kepala BPP, empat Penyuluh, empat Kepala UPJA, dan dua 28 Petani. Penelitian dilakukan pada 4 kecamatan di Kabupaten Pangandaran yaitu Kecamatan Mangunjaya, Kecamtaan Padaherang, Kecamatan, dan Kecamatan Mangunjaya. Penelitian dilakukan pada tanggal 24-25 Oktober 2019.

Dalam Penelitian ini pengumpulan data melalui kuesioner dengan menggunakan skala Likert untuk mencari data primer tentang kualitas manajer, pelatihan manajer dan pengembangan UPJA. Alternatif jawaban kuesioner ditunjukkan pada Tabel 1.

\begin{tabular}{cc}
\multicolumn{2}{c}{ Tabel 1.} \\
\hline Skor & Keterangan nilai kuesioner \\
\hline 1 & Sangangan Jawaban Kurang \\
2 & Kurang \\
3 & Cukup \\
4 & Baik \\
\hline
\end{tabular}

Pada penelitian ini, data dianalisis secara deskriptif dan statistika. Teknik analisis data menggunakan bantuan software statistik yaitu Statistical Product and Service Solution (SPSS).

Menurut Sugiyono (2010), analisis deskriptif merupakan analisis statistik yang digunakan untuk menganalisis data dengan cara mendeskripsikan dan menggambarkan data yang telah terkumpul. Data penelitian dinyatakan dalam angka dan dianalisis dengan teknik statistik.

Uji $F$ bertujuan untuk mengetahui pengaruh kualitas manajer UPJA $\left(X_{1}\right)$, dan pelatihan manajer UPJA $\left(X_{2}\right)$ terhadap perkembangan UPJA $(Y)$ di Kabupaten Pangandaran.

\section{HASIL DAN PEMBAHASAN}

Data hasil penelitian dianalisis secara deskriptif dengan bantuan Microsoft Excel. Kinerja UPJA dikategorikan kedalam empat kriteria yaitu baik, cukup, kurang, dan sangat kurang.

\section{a. Kualitas Manajer}

Hasil analisis deskripsi variabel kualitas manajer ditunjukkan pada Gambar 1. 


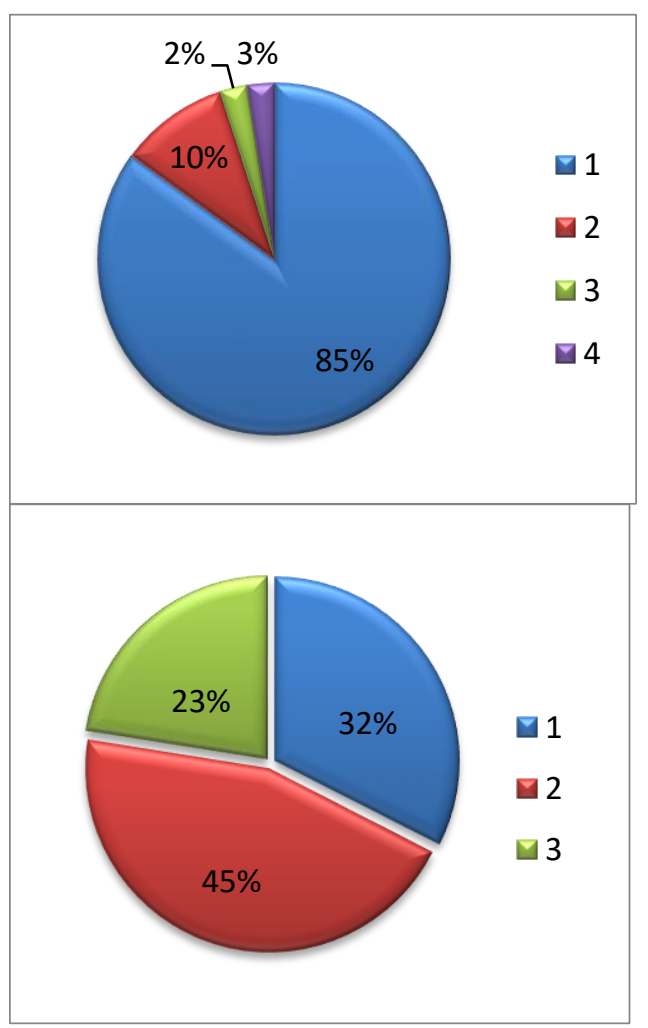

Gambar 1. Kualitas Manajer UPJA Berdasarkan Gambar 1, dapat diketahui bahwa sebanyak $32 \%$ sangat kurang, $45 \%$ kurang, dan 23\% cukup.

\section{b. Pelatihan Manajer}

Hasil analisis deskripsi variabel pelatihan manajer UPJA ditunjukkan pada Gambar 2.

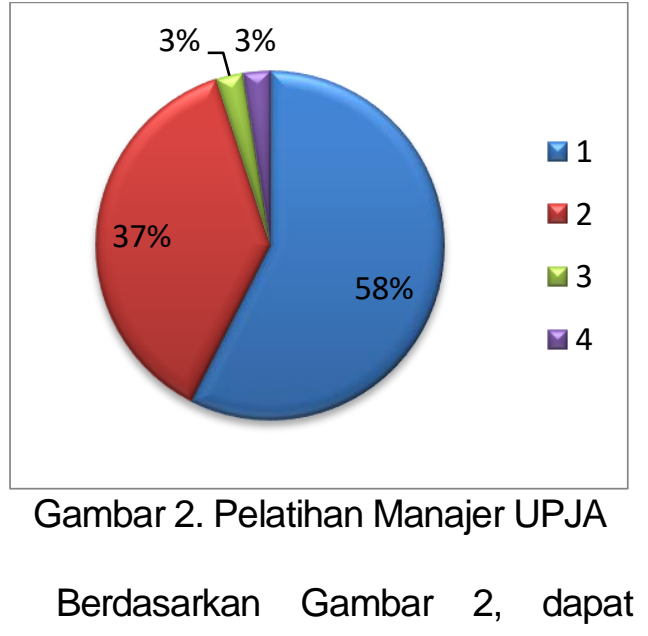
diketahui bahwa sebanyak $58 \%$ sangat kurang, 37\% kurang, 3\% cukup, dan $3 \%$ baik.

\section{c. Pengembangan UPJA}

Hasil analisis deskripsi variabel pengembangan UPJA digambarkan pada Gambar 3.

Gambar 3. Pengembangan UPJA

Berdasarkan Gambar 3, dapat diketahui bahwa sebanyak $85 \%$ sangat kurang, 10\% kurang, $2 \%$ cukup, dan 3\% baik.

\section{Pengujian Hipotesis}

Hasil analisis Uji $F$ menggunakan SPSS ditunjukkan pada Tabel 2.

Tabel 2. Hasil Uji F

\begin{tabular}{|c|r|r|r|r|r|}
\hline Model & $\begin{array}{c}\text { Sum of } \\
\text { Squares }\end{array}$ & Df & $\begin{array}{c}\text { Mean } \\
\text { Square }\end{array}$ & F & Sig. \\
\hline 1 & 8.684 & 2 & 4.342 & 25.534 & $.000^{\mathrm{b}}$ \\
& 6.291 & 37 & .170 & & \\
& 14.975 & 39 & & & \\
\hline
\end{tabular}

Berdasarkan table 2, nilai $\mathrm{F}$ hitung (25.534) > F tabel (3.24) dengan nilai 
signifikansi sebesar $0.000<0.05$ $(\alpha=5 \%)$. Dari hasil ini dapat disimpulkan bahwa kualitas dan pelatihan manajer UPJA secara simultan berpengaruh terhadap Perkembangan UPJA.

Hasil analisis menunjukan variabel kualitas manajer UPJA $\left(X_{1}\right)$ dan pelatihan manajer UPJA $\left(\mathrm{X}_{2}\right)$ berpengaruh secara signifikan dan simultan terhadap perkembangan UPJA (Y) di Kabupaten Pangandaran.

\section{Strategi Peningkatan Kinerja UPJA}

Pelatihan mengenai Identifisakasi suatu wilayah perlu diterapkan. Hal ini terkait dengan ketapatan suatu alsintan dengan kondisi daerah setempat. Apabila pemberian alsintan dari pemerintah tidak sesuai dengan kebutuhan yang diharapkan maka manajer perlu diberikan pelatihan tentang prosedur pengambilan keputusan. Misalkan dengan cara mengirim surat ke pemerintah mengenai permohonan penggantian atau pertukuran alsintan yang lebih sesuai dengan kondisi topografi wilayah. Hal ini juga perlu disesuaikan dengan peraturan yang berlaku. Harapnnya alsintan yang sesuai dengan keadaan wilayah tersebut dapat mendorong keinginan petani untuk menyewa alsintan millik UPJA. Penyewaan alsintan yang meningkat dapat menambah pemasukan UPJA, meningkatkan produktivitas tanaman, efisiensi waktu, dan efisiensi biaya operasi.

Manajer juga diberikan pelatihan agar dapat menarik para pemuda untuk berusaha tani. Berdasarkan hasil penelitian ini, petani tidak ingin anaknya menjadi seorang petani. Mereka beranggapan bahwa pertanian merupakan pekerjaan yang kotor dan tidak menguntungkan. Padahal banyak orang-orang kaya di indonesia berbisnis pada bidang pertanian. Oleh karena itu, diperlukan peran seorang manajer yang dapat mengajak pemuda untuk berbisnis dibidang pertanian melalui pendekatan digital marketing.

\section{Strategi Pelatihan IPTEK}

Dengan meningkatnya kecanggihan zaman sehingga membuat cepatnya pertukaran informasi, serta ketersediaan media informasi yang dapat dijangkau berabagai kalangan membuat pelatihan mengenai digital marketing perlu diterapkan kepada para manajer. Pelatihan digital marketing berfungsi untuk memperluas pasar penyewaan alsintan oleh UPJA. Manajer harus bekerjasama dengan UPJA di kecamatan lainnya. Hal ini bertujuan agar informasi tentang UPJA dapat tersebar luas.

Tahap pelatihan yang pertama adalah membuat akun google atau yahoo. Selanjutnya, manajer dilatih untuk menggunakan aplikasi UPJA 
mobile. Selain itu, UPJA juga dilatih untuk menggunakan aplikasi SIKATAM untuk mempermudah penentuan harga sewa alsintan. Kedua aplikasi tersebut dikembangkan oleh Kementerian Pertanian. Pada tahap akhir, manajer UPJA dilatih untuk promosi menggunakan social media. Penggunaan social media ini perlu dimanfaatkan secara maksimal sehingga masyarakat pertanian khusunya kaum muda dapat tertarik, sosial media yang paling digunakan masyarakat adalah facebook, instagram, tweeter, dan youtube. Dengan adanya pelatihan mengenai sosial media diharapkan manajer dapat memahami mengenai perkembangan zaman yang cepat sehingga media informasi dapat dimanfaatkan. Namun perlu mengutamakan segmentasi pasar sehingga penyewaan alsintan tidak terlalu jauh dan biaya transportasi rendah.

\section{Pelatihan manajemen SDM}

Sumberdaya manusia merupakan kunci dari keberhasilan suatu program pemberdayaan petani (Wardani, 2015). Menurut (Yeni dan Dewi, 2014), pengembangan sumber daya manusia UPJA perlu dilakukan dengan restrukturisasi organisasi yang memisahkan antara pengelolaan alsintan pada sub-sistem on-farm dan off-farm. Hal ini bertujuan untuk menyederhanakan sekaligus memperkuat posisi personil organisasi pada fungsi dan kegiatan masingmasing, misalnya bagi manajer, operator, pengelola keuangan atau pengawas. Sosialisasi dan Penyuluhan kepada petani terkait dengan stakeholders tentang pentingnya organisasi dengan sistem UPJA perlu dilaksanakan, pelatihan yang diberikan manajer adalah manajemen SDM yang dimiliki maupun sekitar wilayah tersebut. Dalam hal ini, manajer mendapat pelatihan dengan materi permentan No.25 tahun 2008 tentang Pedoman dan Penumbuhan dan Pengembangan Usaha Pelayanan Jasa Alat dan Mesin Pertanian (UPJA). Selain itu manajer juga harus memberikan pelatihan kepada para opertaor ataupun mekanik mengenai K3 dan pelayanan sehingga menghasilkan SDM yang unggul serta kepuasan pelanggan. Selain itu, karyawan dapat memahami tugas pokoknya masing-masing. Manajer juga mendapat pelatihan mengenai prosedur kerjasama atau bermitra dengan UPJA lainya bahkan perusahaan-perusahaan alsintan dan penyedia suku cadang untuk mesin pertanian. Manajer mendapat pelatihan tentang tata cara untuk meningkatkan kualitas pelayanan seperti kecepatan respon pelayanan yang diberikan, dan 
biaya sewa yang sesuai dengan keadaan daerah.

\section{Pelatihan Manajemen Keuangan}

Manajemen keuangan perlu dilaksanakan dalam setiap organisasi termasuk UPJA. Manajer selaku penanggung jawab membutuhkan pelatihan manajemen keuangan (Yeni dan Dewi, 2014). Permasalahan keuangan UPJA di Kabupaten Pangandaran adalah metode pembayaran petani masih berupa natura. Selain itu, peminjam merupakan anggota kelompok tani itu sendiri sehingga pembayarannya lambat. Padahal untuk menjalankan bisnis butuh tindakan profesional sebaiknya pembayaran dilakukan diawal dan pelunasanya pada akhir pengembalian alsintan.

Perawatan pada alsintan perlu dilakukan untuk menjaga kondisi alsintan tetap optimal perawatan yang dilakukan yakni ketika sudah selesai pekerjaan, perawatan 40 jam kerja dan 100 jam kerja. Perawatan yang dilakukan seperti penggantian oli mesin pelumas dengan 40 SAE dan pada bearing atau alat berputar menggunakan Grease Oil 90 SAE, kemudian filter udara, dan tune up mesin. Perawatan ini memerlukan biaya, seorang manajer perlu menyisihkan sebagian dari pendapatan untuk perawatan alsintan. Selain itu, manajer juga harus dapat mengatur pemberian gaji kepada para karyawanya.

\section{SIMPULAN}

Berdasarkan hasil analisis dan pembahasan sebelumnya, simpulan yang dapat diambil adalah bahwa terdapat pengaruh yang simultan antara kinerja dan kualitar manajer UPJA terhadap perkembangan UPJA. Oleh karena itu, dibuatlah strategi pengembangan manajer UPJA yang mampu mendorong kemajuan UPJA di Kabupaten Pangandaran. Strategi tersebut antara lain Pelatihan identifikasi potensi wilayah, Pelatihan IPTEK, Pelatihan manajemen SDM, dan Pelatihan Manajemen Keuangan.

\section{UCAPAN TERIMAKASIH}

Dalam penyusunan penelitian ini, penulis berterimakasih sebesarbesarnya kepada yaitu sebagai berikut:

1. Kepala BPP, penyuluh, Kepala UPJA dan petani Kecamatan Pangandaran, Kecamatan Cimerak, Kecamatan Padaherang, dan Kecamatan Mangunaya di Kabupaten Pangandaran.

2. Tim Dosen Kelompok 2 Penelitian Prodi Teknologi Mekanisasi Pertanian. 
3. Ibu Intan Kusuma Wardani, S.TP., M.Sc dan Ibu Erniati, S.TP., M.Sc selaku pembimbing.

4. Rekan-rekan yang berkontribusi dalam penyelesaian penyususnan penelitian ini.

\section{DAFTAR PUSTAKA}

Hamidah, dan Soedarto T. 2006. Analisis Operasional Traktor Tangan pada Usaha Pelayanan Jasa Alsintan Pola Kerasama Operasional di Kabupaten Gresik. Jurnal IImu-IImu Ekonomi. Vol. (6) No. 2 : 76-85.

Sugiyono. 2010. Metode Penelitian Kuantitatif, Kualitatif dan R\&D. Alfabeta: Bandung.

Yeni F. dan Dewi N. 2014. Analisis Sistem Unit Pelayanan Jasa Alsintan (UPJA) Di Kecamatan Kuala Kampar Kabupaten Pelalawan. Jurnal Dinamika Pertanian. Vol. (29) : 169-182.

Wardani I.K. 2015. Strategi Peningkatan Kinerja Pengelolaan Irigasi Pada Perkumpulan Petani Pemakai Air Dalam Proses Menuju Modernisasi Irigasi Di Tingkat Tersier. Tesis. Universitas Gadjah Mada. 